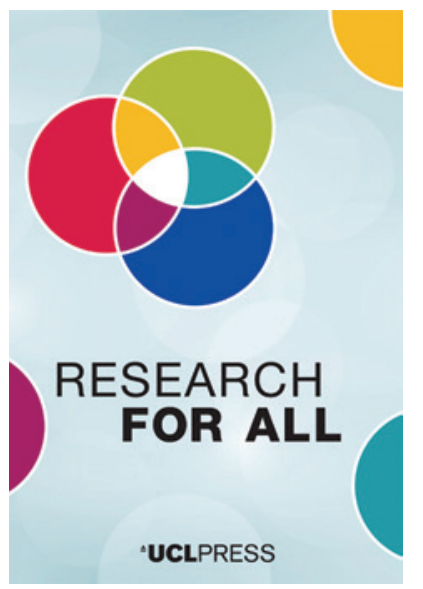

${ }^{ \pm}$CLPRESS

\section{RESEARCH FOR ALL}

The open-access journal for public engagement with research

ISSN 2399-8121 (Online)

Journal homepage:

https://www.uclpress.co.uk/pages/research-for-all

\title{
The Future of Our Seas: Marine scientists and creative professionals collaborate for science communication
}

\author{
Laurence De Clippele (D), Madlaina Michelotti (D, Charlotte R. Findlay (D,

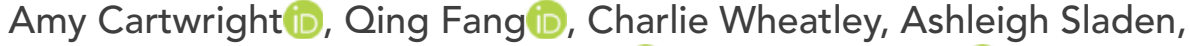 \\ Kes Scott-Somme, Harry R. Harding D, Juliette Jackson (D, \\ Laura E. Hepburn, Jessica Giannotti, Grace Carroll, Nicole Heidtke, \\ Alison M. Worrall and Kris De MeyeriD
}

\section{How to cite this article}

De Clippele, L., Michelotti, M., Findlay, C.R., Cartwright, A., Fang, Q., Wheatley, C., Sladen, A., Scott-Somme, K., Harding, H.R., Jackson, J., Hepburn, L.E., Giannotti, J., Carroll, G., Heidtke, N., Worrall, A.M. and De Meyer, K. (2021) 'The Future of Our Seas: Marine scientists and creative professionals collaborate for science communication'. Research for All, 5 (1), 134-56. https://doi.org/10.14324/RFA.05.1.11

Submission date: 26 June 2019

Acceptance date: 14 October 2020

Publication date: 16 February 2021

\section{Peer review}

This article has been peer-reviewed through the journal's standard double-blind peer review, where both the reviewers and authors are anonymized during review.

\section{Copyright}

(C) 2021 De Clippele, Michelotti, Findlay, Cartwright, Fang, Wheatley, Sladen, Scott-Somme, Harding, Jackson, Hepburn, Giannotti, Carroll, Heidtke, Worrall and De Meyer. This is an openaccess article distributed under the terms of the Creative Commons Attribution Licence (CC BY) 4.0 https://creativecommons.org/licenses/by/4.0/, which permits unrestricted use, distribution and reproduction in any medium, provided the original authors and source are credited.

\section{Open access}

Research for All is a peer-reviewed open-access journal. 


\title{
The Future of Our Seas: Marine scientists and creative professionals collaborate for science communication
}

\author{
Laurence De Clippele* - University of Edinburgh, UK \\ Madlaina Michelotti* - University of St Andrews, UK \\ Charlotte R. Findlay - Scottish Association for Marine Science (SAMS) and \\ University of the Highlands and Islands, UK \\ Amy Cartwright - University of Plymouth, UK \\ Qing Fang - University of Aberdeen, UK \\ Charlie Wheatley - Jacobs, London, UK \\ Ashleigh Sladen - University of Plymouth, UK \\ Kes Scott-Somme - University College London, UK \\ Harry R. Harding - University of Bristol, UK \\ Juliette Jackson - Seadream Education CIC, Kingsbridge, UK \\ Laura E. Hepburn - University of Stirling, UK \\ Jessica Giannotti - Scottish Marine Institute, Oban, UK \\ Grace Carroll - Templar Arts and Leisure Centre (TALC), Argyll, UK \\ Nicole Heidtke - Templar Arts and Leisure Centre (TALC), Argyll, UK \\ Alison M. Worrall - Aquarela Images, Macclesfield, UK \\ Kris De Meyer - King's College London, UK
}

\begin{abstract}
To increase awareness of the current challenges facing the marine environment, the Future of Our Seas (FOOS) project brought together the expertise of scientists, public engagement experts and creatives to train and support a group of marine scientists in effective science communication and innovative public engagement. This case study aims to inspire scientists and artists to use the FOOS approach in training, activity design and development support (hereafter called the 'FOOS programme') to collaboratively deliver novel and creative engagement activities. The authors reflect on the experiences of the marine scientists: (1) attending the FOOS communication and engagement training; (2) creating and delivering public engagement activities; (3) understanding our audience; and (4) collaborating with artists. The authors also share what the artists and audiences learned from participating in the FOOS public engagement activities. These different perspectives provide new insights for the field with respect to designing collaborative training which maximizes the impact of the training on participants, creative collaborators and the public. Long-term benefits of taking part in the FOOS programme, such as initiating future collaborative engagement activities and positively impacting the scientists' research processes, are also highlighted.
\end{abstract}

Keywords: science communication, public engagement, art-science collaboration, communication training, public event delivery 
Key messages

- A bespoke environmental science communication and public engagement training in combination with delivering a public event allowed the marine scientists to learn from experience and led to a lasting change to their practice as communicators and researchers.

- A culture of soliciting feedback from peers, creative professionals, friends, family and even random strangers was important for creating public engagement activities which were innovative and spoke to a wide audience.

- Art-science collaborations allowed the marine scientists and artists to develop creative outputs with the potential to be more influential than a scientific paper, directly affecting the creative collaborators involved and the public taking part in the activities.

\section{Introductory note}

The authors are a group of marine scientists (early career researchers, young industry professionals and conservation enthusiasts) and artists/creative professionals. The majority of this article is written from the perspective of the marine scientists. When written from the perspective of the artists, this is specified.

\section{The Future of Our Seas programme}

The Future of Our Seas (FOOS) consortium consisted of scientists, public engagement professionals and creatives, who together provided a three-day interactive classroombased training programme to remedy the lack of science communication and public engagement training for environmental scientists in particular. The training addressed the following specific objectives: (1) understanding the different roles scientists can adopt in science communication and policymaking; (2) understanding the psychology behind forming opinions and values to help tailor a scientific message to a target audience on the potentially sensitive and contested nature of marine science topics; (3) working with artists/creative professionals and public engagement organizations; (4) developing engaging story arcs; and (5) planning the delivery of a public engagement activity. Sharing experiences, and requesting and providing feedback was an integral part of the FOOS training programme.

Despite the diverse professional backgrounds of the marine scientists, their motivations to apply to the FOOS training programme were similar and three-fold: (1) 'we carry a sense of obligation to share scientific knowledge with non-experts';

(2) 'we are striving to become better scientists, professionals and communicators'; and

(3) 'we recognize the importance of the transferable skills which can be acquired'.

\section{Purpose and availability of communication and engagement training}

Within the scientific community, scientists often share similar motivations for participating in public engagement. Sharing research with others was found to improve academic performance (Jensen et al., 2008; Staley, 2017), develop professional skills, provide personal enjoyment and change the audiences' priorities, values and attitudes (Jensen et al., 2008; Besley et al., 2015; Hamlyn et al., 2015; Staley, 2017; Cerrato et al., 2018). Engaging with the public can also attract more funding (Andrews et al., 2005), contribute 
directly to the university Research Excellence Framework (REF) reports, and help achieve responsible research and innovation (European Commission, 2015).

Although science communication and engagement are expanding areas, and attitudes towards them are changing, there is still a lack of support and opportunities available to enable scientists to engage with the public/policymakers as much as they would like (Hamlyn et al., 2015). Time restrictions, and a lack of funding, knowledge, training and institutional recognition, can all prevent recurring participation in public engagement activities (Hamlyn et al., 2015; Cerrato et al., 2018). Professional training can address some of these barriers while appealing to people's motivations for engaging with the public (Cerrato et al., 2018). However, there is a current lack of training opportunities in both the academic and the professional world (Besley and Tanner, 2011). Baram-Tsabari and Lewenstein (2017) provide an overview of the different types of science communication training that have been described in the literature. This overview found that most training opportunities either focus on a particular communication context (for example, writing popular articles, being interviewed on television) or on a specific educational context (for example, the design of particular training programmes). A survey in the UK found that only 28 per cent of scientists received formal communication or public engagement training between 2010 and 2015 (Hamlyn et al., 2015). The training they did receive mostly focused on engaging with the news and on social media, as well as public speaking (Hamlyn et al., 2015).

Baram-Tsabari and Lewenstein (2017) stress the importance of defining the learning goal of communication and engagement training. One of the goals of the FOOS programme was for the marine scientists to be able to engage with a variety of audiences using active and passive engagement methods.

\section{What the marine scientists learned from the FOOS training and activity development}

Understanding the different roles which scientists can adopt helped us to better understand what strategy to choose when engaging with a particular audience.

During the training, we learned that scientists can adopt five roles that can be used throughout different stages and contexts of their careers. These roles are described as the pure scientist, the science arbiter, the science communicator, the honest broker of policy alternatives, and the issue advocate (Rapley and De Meyer, 2014: 745; see Table 1).

$\begin{aligned} & \text { Table 1: Brief descriptions of the professional roles scientists can adopt throughout } \\
& \text { their careers }\end{aligned}$
\begin{tabular}{ll}
\hline Roles & Brief description \\
\hline Pure scientist & $\begin{array}{l}\text { Focuses on generating facts to advance knowledge, but does not } \\
\text { connect with the public or decision-makers. }\end{array}$ \\
Science arbiter & $\begin{array}{l}\text { Responds to questions asked by decision-makers with factual answers } \\
\text { but does not respond with 'what should be done'. }\end{array}$ \\
Science & $\begin{array}{l}\text { Actively engages with society to present scientific results, providing } \\
\text { communicator }\end{array}$ \\
Honest broker of interpretation and drawing attention to potential implications. \\
policy alternatives
\end{tabular}
$\begin{aligned} & \text { Contributes scientific expertise to decision-makers to ensure all } \\
& \text { available policy choices are fully explored and evaluated, providing a } \\
& \text { cooperative way forward. } \\
& \text { Issue advocate }\end{aligned}$
$\begin{aligned} & \text { Engages with decision-makers and the public to promote one particular } \\
& \text { course of action based on their expertise and understanding. }\end{aligned}$

Source: edited from Rapley and De Meyer (2014: 745). 
Understanding each role enabled us to adapt our communication style and type of response to address specific requirements. We learned that it is important to understand what is required of a role when adopting one, and to differentiate clearly between expressing our opinions as concerned citizens and stating scientific facts when communicating. Ultimately, adopting roles other than the 'pure scientist' character is beneficial not just to society but also to the scientific community (Rapley and De Meyer, 2014: 745). Adoption of alternative roles can help gather the talents and efforts of people outside the scientific community, thus strengthening the scrutiny of the scientific process, inspiring trust, generating public interest and increasing the robustness of scientific research (Rapley and De Meyer, 2014: 745).

Understanding the psychology of how people form opinions helped us to tailor scientific messages to our target audience.

Different people engage on different levels with certain topics. The FOOS training exemplified the importance of acknowledging values, life experiences and interpretations that may conflict with our own. By understanding and considering alternative perspectives, we learned that it is possible to tailor a particular message to a wider target audience more efficiently. During our FOOS training, we discussed 'value modes' - a model that groups people with similar sets of values (things that are important to them in life) (Rose, 2011). Table 2 provides examples of tailored messages for certain value groups. This model was used during the planning and development of our public engagement activities. By talking directly to people's values, such as pride and nostalgia, we were more likely to engage with the public on a personal level. For instance, raising awareness of Scotland's deep-sea coral reefs might encourage British people to protect a habitat that is a unique and an invaluable part of their seafaring heritage (see Activity 5, below).

When attempting to explain our research, we found that we often presented an overwhelming and dense monologue. We learned that providing too much detailed and technical knowledge about a specific topic is often a barrier to effective communication, and the challenge of simplifying a topic or message is one that many

\begin{tabular}{|c|c|c|}
\hline Value group & Values & Topic tailored towards value type \\
\hline Settler & $\begin{array}{l}\text { Safety, belonging, security, } \\
\text { stability, home, nostalgia }\end{array}$ & $\begin{array}{l}\text { Focus on the local environment. Engage } \\
\text { audience by tapping into memories of } \\
\text { experiences with that environment. Offer ideas } \\
\text { about how participants are connected to and can } \\
\text { safeguard these precious places through simple } \\
\text { measures. }\end{array}$ \\
\hline Prospector & $\begin{array}{l}\text { Self-esteem, the esteem } \\
\text { of others, achievement, } \\
\text { recognition, national pride }\end{array}$ & $\begin{array}{l}\text { Focus on the resources from the habitat, which } \\
\text { could benefit them. Engage audience by } \\
\text { highlighting solutions to how these resources } \\
\text { can be protected and the economic cost and } \\
\text { reward of doing so. }\end{array}$ \\
\hline Pioneer & $\begin{array}{l}\text { Ethics, ideas, innovation, } \\
\text { progress, learning, } \\
\text { personal development }\end{array}$ & $\begin{array}{l}\text { Focus on understanding the importance of the } \\
\text { habitat, and what would be lost if degraded. } \\
\text { Engage audience by advising how they can } \\
\text { contribute to a deeper understanding of our } \\
\text { environment and how they can make a difference } \\
\text { by engaging others (settlers and prospectors). }\end{array}$ \\
\hline
\end{tabular}

Note: 'Values' column edited from Rose (2011); 'Topic tailored' column is how we applied the insights of Rose (2011) to the issue of habitat degradation. 
Figure 1: Visual example of having a two-way conversation during the 'Mighty Louis the Mussel' game activity (see Activity 1, below) (photograph: Ben Loveday)

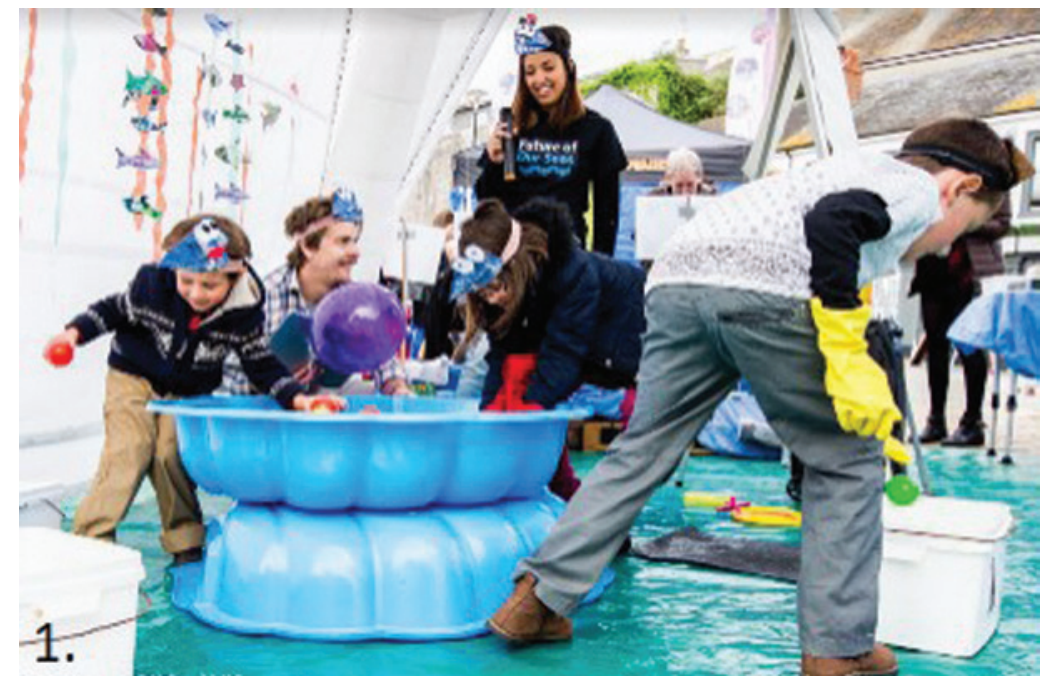

scientists face (Kwok, 2013). To avoid this, we developed and practised our own elevator pitch, a skill that is mostly taught to people working in sales and business (Pincus, 2007). An elevator pitch is a brief, persuasive and digestible face-to-face speech that gives a summary of your background, your research or what your organization does (Pincus, 2007; Kwok, 2013). Having developed our elevator pitch during the FOOS training, we were tasked to refine it by engaging with different people. Many of us took this task to heart and spoke to people on the train, the bus, in the park and even at our local corner shop. This allowed us to apply our training to attempt to spark the interest of a random audience and learn from their reactions to subsequently improve our communication approach.

Through this experience, we learned that people were more likely to engage with us and remember the communication event if we actively involved them in thinking about and discussing our topic in a two-way conversation (Figure 1).

When tailoring a message or event, we also learned that it is beneficial to restrict a message to a few simple take-away points, as people are more likely to remember information if it is delivered as a simple, bite-sized message (Maibach, 2012: 105, Myers et al., 2015). To make our messages relatable, we often compared quantities or sizes to common items. These comparisons helped us to create a visual connection between the participant and our message. For example, describing the amount of plastic in our oceans in terms of tonnes or volumes may not be helpful; however, explaining that seven busloads of plastic washed up on a beach last year gave our audience a relatable visual to remember.

We also found value in using non-controversial language and approaching our message in an unexpected and creative way, especially when we were communicating about a topic such as ocean acidification, which is rather abstract and a challenge to get across if people have either never heard about it or have preconceived ideas about what the language means. For example, we created postcards and magnets using fun illustrations and simple language to explain some of the unexpected but concrete and tangible effects that ocean acidification can have on animals. This allowed our audience to relate to the message more easily than if we had provided a technical description of changing ocean chemistry (Figure 2). 
Figure 2: Example of using creativity to communicate a challenging topic during the plastics and acid activity (see Activity 7, below) (credit: Charlie Wheatley)
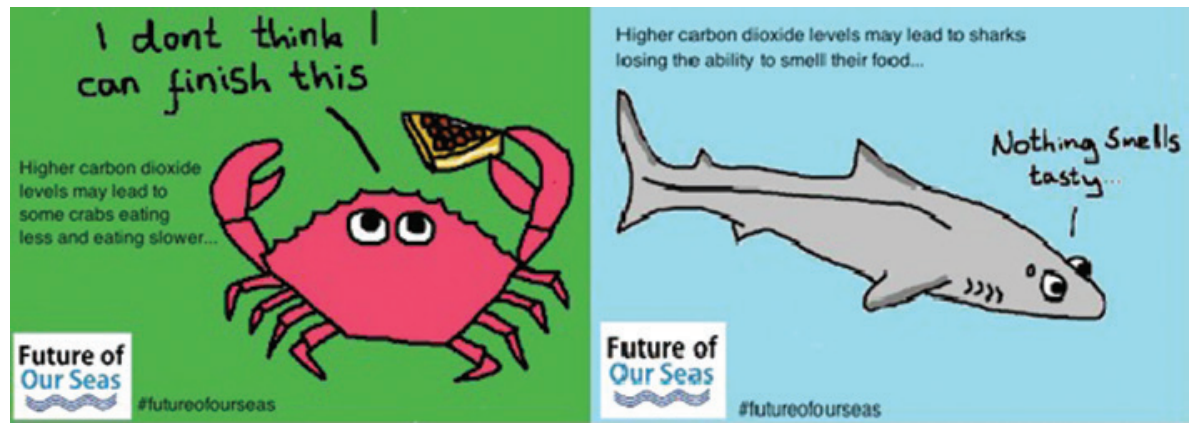

We also learned that effective activities and messages should avoid 'doom and gloom', as a sense of despair may decrease interest in the subject and discourage the public from taking meaningful actions (Mayer and Smith, 2019). Instead, a message which fosters wonder, and offers solutions and ways to get involved, is likely to have a more positive impact on the audience's perception of the environmental issue and what needs to be done about it.

\section{Networking with artists and creative professionals}

As part of the training course, the FOOS trainers organized a networking session with local creatives, including visual and sculptural artists, a dancer, a videographer, a documentary maker, a creative writer and an ocean-inspired textile designer. This networking session aimed to: (1) put our newly learned skills into practice and pitch our research to non-scientists; (2) engage in creative brainstorming to come up with novel engagement ideas; and (3) facilitate potential collaborations for the development of our engagement activity.

In small groups, we presented an elevator pitch to creative professionals and artists to introduce our research interests and start a two-way conversation with them. These conversations were crucial and benefited us by providing an opportunity to share ideas with a creative community. Discussing scientific topics with people from a different professional background, who think and communicate in different ways, helped shape the designs of some of our engagement activities. This networking session directly led to the collaborative development of the Beautifully Strange and Sounds of the West Coast (Activities 2 and 6, below) activities. Two collaborating community partners were involved in designing, building and delivering the event. More details on the experience and benefits of these collaborations can be found below.

Overall, having discussions and collaborating with creative professionals and artists during the networking session added value to our training, as they offered creative and innovative ideas for communicating our scientific messages. Working with scientists was also beneficial for some of the artists, as it provided them with the opportunity to use their art to communicate new messages and to expand their own networks.

\section{Story arcs and how to craft your story}

After understanding how to effectively communicate messages, the focus of the training transitioned to the development of our own public engagement activities. 
We explored the importance of constructing an engaging story arc for a specific target audience. A story arc is a narrative trajectory that refers to the chronological construction of a plot in a story or, in our case, a public engagement activity. Generally, a story arc starts by introducing the setting, followed by a rising action encouraging the audience to engage, leading to a climax which often incorporates an element of surprise. Finally, the climax unfolds, and the science communicator resolves and concludes their narrative (Hirsch and Nisbet, 2007; Lee et al., 2010; Cohn, 2013). An example is given in Box 1.

Box 1: Story arc - Scotland's cold-water coral reef, the Mingulay Reef

Introducing the setting: a conversation was sparked by using mysterious touch boxes mimicking exploring the dark, unknown deep sea. These boxes contained clues to inspire interest in and care for cold-water coral reefs.

Rising action: using a photograph exhibition and a 'count the number of crabs' challenge, the beauty of cold-water coral reefs was revealed to the audience.

Climax unfolds: a table with corals, brittle stars, worms and sponges from the Mingulay Reef was presented to the audience. The audience had the chance to hold these animals and interact with the scientist. This was accompanied with a video of the Mingulay Reef, allowing people to see what their national reef looks like.

During the FOOS training, we also used a specific exercise where we created three visual representations of our research, to understand that there are multiple lenses we can use to engage audiences in our research. Using a range of available craft materials, we depicted the following scenarios: (1) a specific event showing what we do in our jobs; (2) something that summarizes our subject areas; and (3) the importance of our subjects in relation to the marine environment. In Figure 3, the ball on the left represents an ecologist studying the biodiversity of cold-water coral reefs, the ball in the middle represents cold-water coral mounds and the ball on the right shows the importance of studying coral morphology to understand the effects of local currents. The exercise pushed us to discover different ways of communicating our research. Once our three-lenses visuals were completed, we created a physical network connecting similar interests, with a different coloured ribbon for each of the three lenses (see Figure 4). These connections encouraged us to find common ground between topics where a link was not immediately obvious. The groups in which we planned and delivered our public engagement activities were based on the connections that were discovered during this exercise. For example, man-made underwater noise was linked to coastal and maritime cultural heritage on the west coast of Scotland, due to the link between changes in cultural heritage (for example, an increase in ocean-based tourism and industry) and the subsequent underwater noise created by these activities (for example, an increase in shipping noise from ferries transporting tourists to Scottish islands) (see Activity 6, below). Another activity connected two research areas through an organized beach walk, in which the audience learned about lichen and small creatures living on the shoreline, but also found plastics among these shoreline creatures. This activity thus instilled a sense of wonder about the natural world, but it combined that with the visible threat of plastic pollution and messages about what people can do about it (see Activity 8 , below). 
Figure 3: A visual representation of research through three different lenses (photo: Laurence De Clippele)

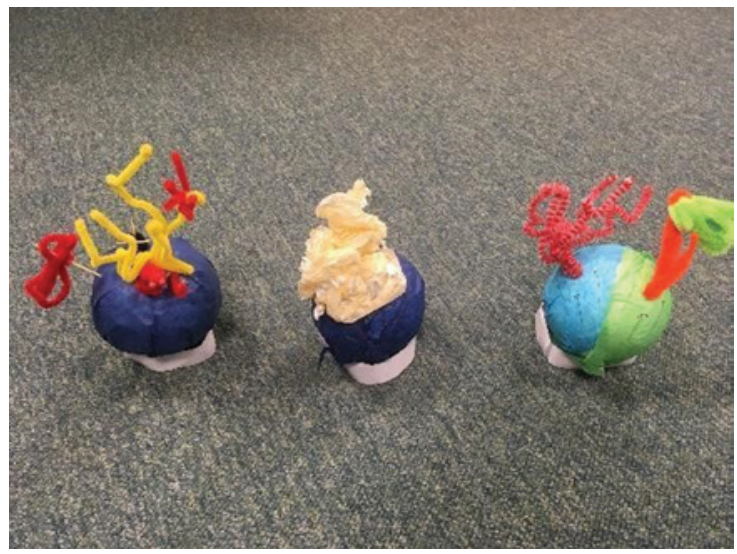

Figure 4: Connecting our research interests, represented by our crafted research representations, with ribbons (credit: Aquarela Images)

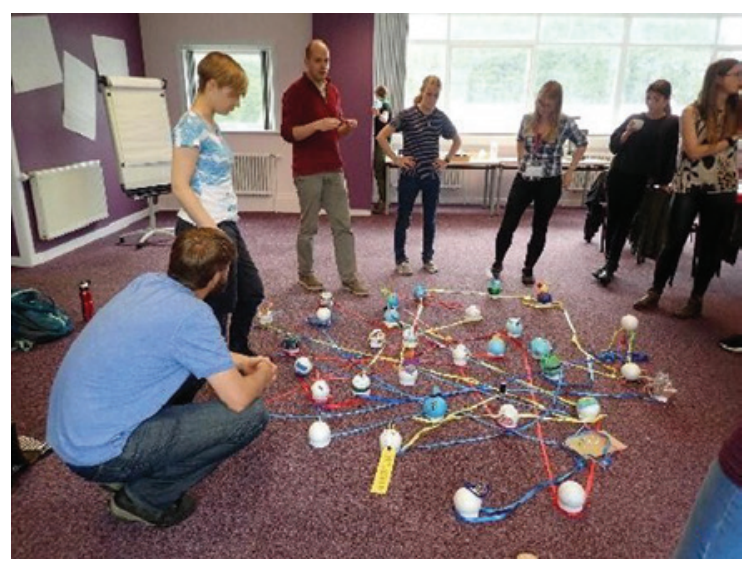

\section{Planning the delivery of a public engagement activity}

Event and activity planning started in earnest after the FOOS training, once we had finalized plans for what our specific activity was going to entail. To conceptualize the story arc for our activity, an 'activity design template' was provided to define the purpose, mechanism, audience, experience, evaluation, materials and timing (Figure 5). The template enabled us to fine-tune the activity, as it highlighted any potential problem areas and identified any requirements for additional support or resources which might be required.

Figure 5: Activity design template (credit: Charlotte R. Findlay) ACTIVITY DESIGN TEMPLATE ACTIVITY TITLE: ...

\begin{tabular}{|c|l|l|l|}
\cline { 2 - 4 } \multicolumn{1}{c|}{} & Draft 1 & Feedback & Draft 2 \\
\hline Purpose & & & \\
\hline Mechanism & & & \\
\hline $\begin{array}{c}\text { Audience }+ \\
\text { Experience }+ \\
\text { Evaluation }\end{array}$ & & & \\
\hline $\begin{array}{c}\text { Materials }+ \\
\text { Community }\end{array}$ & & & \\
\hline Timing & & & \\
\hline
\end{tabular}


Fortnightly discussions and feedback sessions with other participants were organized by the FOOS trainers to support us further during the planning process. The event planning and logistics were led by Incredible Oceans and Invisible Dust, experts in hosting outreach events. As time passed, we received updates on site locations, conditions and available materials (for example, access to a power supply and to water), which allowed us to refine the plans for our activities. At this point, a detailed risk assessment was prepared for each activity.

\section{Developing an idea by giving feedback and sharing experiences}

Feedback was central to our process of developing our engagement ideas, both during and after the training. We received feedback at various stages from the participating scientists, the FOOS trainers and the creative professionals. Receiving continual feedback was an unusual experience for many of us, as a process focused on feedback is not commonly used in the scientific community. Receiving regular feedback on our ideas was key for their development, and it benefited us due to its powerful influence on our learning processes. Feedback was also important to stimulate inspiration when developing an activity after the training. In addition, we discussed ideas with colleagues, friends and family, which provided new perspectives and enabled further development of our engagement activity.

\section{Organizing an activity as a team: Group collaboration tools}

Good communication is key for organizing a successful event, but it can be challenging when the people involved are geographically widespread. This was the case for FOOS. To overcome these barriers and support the development of our engagement events, we used two digital communication tools (Slack - Searchable Log of All Conversations and Knowledge; Skype) and an online file storage and sharing service (Google Drive).

Rather than using email, we used Slack to communicate with team members and share files. Slack is a tool that supports team projects by bringing people together, and organizing tasks and conversations (Koetsier, 2013; Kim, 2016). Slack is increasingly being used by the scientific community, and it is widely regarded as a good communication tool for teams (Perkel, 2017: 123).

Group calls were organized every two weeks before the event and one month after the event, using telecommunication software applications. We used these calls to share our progress and our needs, carry out reflective tasks and share feedback. These conversations were useful, as they allowed us to learn from each other and provide support.

\section{What the marine scientists learned from delivering engagement activities \\ Learnings from event organization and delivery}

Running the training in combination with delivering an event was particularly beneficial, as we were able to directly apply our newly acquired theory and skills. Organizing an event requires the organization of a lot of logistics (for example, electricity, tables). Even though we were fortunate to have had support from Incredible Oceans, who, for example, provided us with an inflatable dome in which we delivered our activities (see Figure 6), we learned about the process and importance of well-organized logistics. 
Figure 6: The inflatable dome (credit: Aquarela Images)

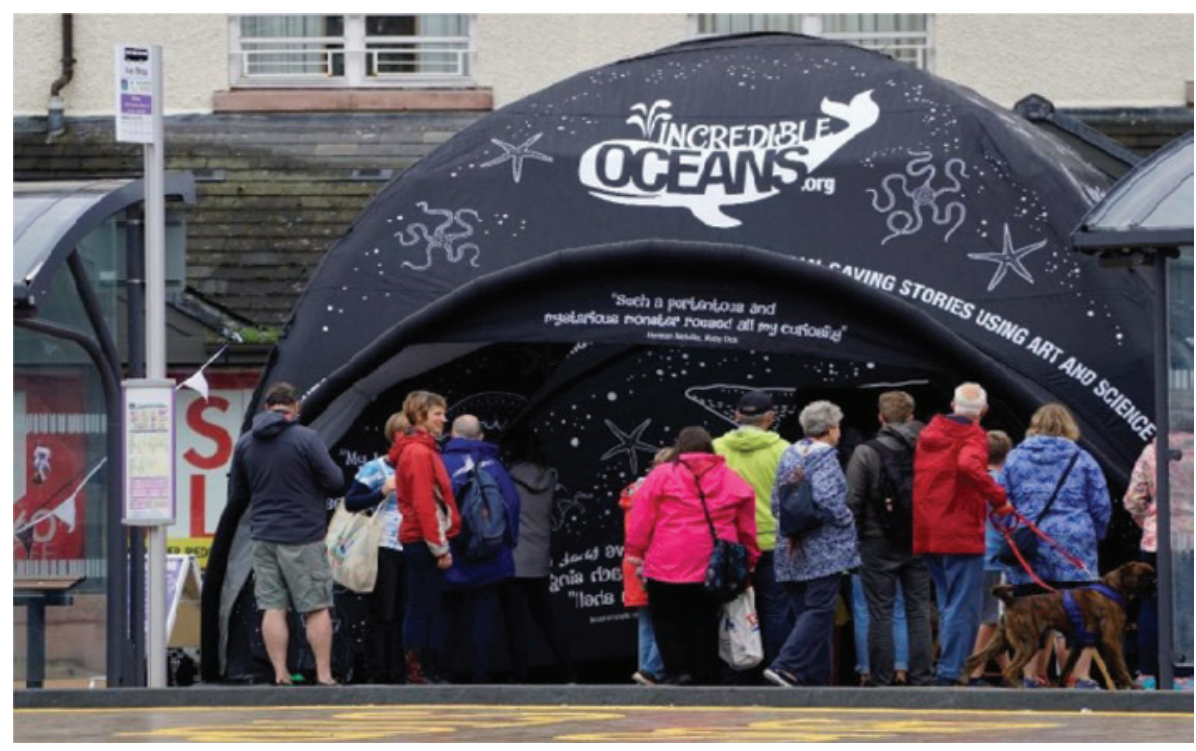

Unfortunately, depending on the activity, time commitment appeared to be a recurring challenge. The time commitment of designing and planning the activities was underestimated by both the FOOS trainers and by us. This affected the ability of some scientists to participate and therefore increased pressure on others. Some of us also experienced issues with arranging time to plan and deliver our events during working hours, and felt that the benefits of this project were not recognized within our organizations. Time constraints especially restricted collaborations with creative professionals and artists. For example, the Sounds of the West Coast activity had to be changed from touchable sound panels to touchable seaweed due to a lack of time to create the original piece. Scientists who were able to commit more time towards the development of their activities gained more from the process as a whole and created activities that they have since been able to reuse for other engagement contexts.

The budget for creating our activities was limited, which caused some to use funds from other sources. However, this also had positive effects, as it enabled some to be more creative in the development of their activity (for example, involving family members to help create marine animal magnets).

Although evaluation data is now required by most funders (NCCPE, 2018a), it is often missing from science engagement activities (Hart and Northmore, 2010). Feedback was gathered from the public during our events via a range of methods. Feedback mechanisms included whiteboards where visitors could write comments, evaluation buckets where people could place a stone to 'vote' for how much they enjoyed the activity, a quantitative questionnaire that also collected non-personal demographic data, and a record of the total number of visitors that attended each activity. From our experience, we believe that there is a need to better understand the various ways of collecting and reporting evaluation data. Training focused on this topic would be helpful for delivering public engagement activities.

Despite designing the activities with a certain target audience in mind, the language, materials and set-up still needed to be tailored on the spot, as our audience varied more than expected. This highlights the importance of communication training that focuses on addressing these challenges prior to organizing public engagement events. 
Since our events ran over a two-day period, we were able to incorporate learnings from the first day into the second day. For example, the theatre piece developed by the team in Plymouth, which aimed to convey research on artificial reefs and marine renewables (see Activity 3, below), relied on audience participation by reading a script and acting different roles. It was devised for a certain age range, but as younger children (who were unable to read) wanted to take part, on the second day the organizers read the script while the audience members (particularly those who were too young to read) wore costumes for their roles and acted alongside the script instead. The activity developed from a 'theatre' into a participatory storytelling session. Adaptations were also made to the design of the event space, which improved participation and activity delivery.

\section{Public engagement activities}

This section presents an overview of some of the public engagement activities that were developed as a result of the FOOS training. The activities aimed to be more participatory, innovative and creative than the average science fair 'table top' experiments and demonstrations.

Activity 1. Mighty Louis the Mussel game: This activity was based on a story of 'Mighty Louis' (Mytilus edulis), a stereotypical French mussel. Participants had to help Mighty Louis prevent pollution in Plymouth by removing contaminants such as copper (red balls), pesticides (yellow balls) and plastic (blue balls). They also had to collect algae (green balls) as food for Mighty Louis, highlighting the importance of algae for bivalve growth and health (see Figure 1).

Activity 2. Beautifully Strange: The entrance to the dome was covered by two large curtains with artistically reimaged deep-sea footage. The black-out effect of the curtains created a cinema in one half of the dome, where a constantly rolling movie projected video footage of hydrothermal environments; in the other half of the tent, UV light from 'spy pens' was used to reveal hidden secrets about deep-sea animals. The science exhibition inspired people to design and paint their own creatures on fabric.

Activity 3. M.I.G.H.T.Y - Marine Institute's Grand Handmade Theatrical Yarns: An interactive, scripted theatre described how humans can create and incorporate 'homes for nature' in the artificial structures that have been put in the sea, such as seawalls and marine renewable energy installations. Audience members played roles and dressed up in various costumes to represent different sea creatures, such as anemones and lobsters, and also scientists and engineers (see Figure 7).

Figure 7: M.I.G.H.T.Y - Marine Institute's Grand Handmade Theatrical Yarns (photograph: Ben Loveday)

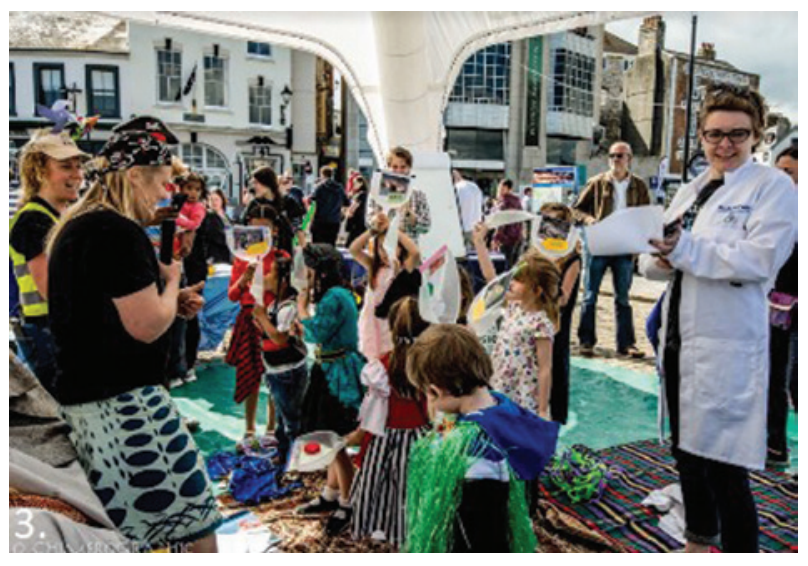


Activity 4. Natural Factory: An interactive jigsaw game gave the participants a vivid experience of how a natural product is synthesized in a host cell. The game used three representative antibiotic drugs as examples, and participants were challenged to piece together the hosts with the final molecules. The activity targeted all age groups and aimed to deliver the message 'nature provides'.

Activity 5. Scotland's Cold-Water Coral Reef: Touch and feel mystery boxes engaged people to think about why society should care about Scotland's cold-water coral reef, such as its importance as a home for fish that end up on our plate, and as a place where medical drugs can be discovered. The public was shown the beauty of the reef through a photographic exhibition, a video and some real pieces of coral (see Figure 8).

Activity 6. Sounds of the West Coast: Seaweed played sounds heard above and below water when touched. Sounds ranged from biological 'natural' sounds such as dolphin whistles, to those made by humans such as large boats and seal scarers (or acoustic deterrent devices) used at fish farms. If touched one after the other, all sounds would play at once to highlight the cumulative effects of lots of activities making noises in our oceans. The activity highlighted the potential for human activities in our oceans to cause large amounts of underwater noise pollution, but it also illustrated the simplicity of removing the problem by simply turning off the sounds.

Activity 7. Plastics and Acid: Focusing on unwanted additions to the marine environment, this session included two subject areas: plastic in the marine environment, and the effects of ocean acidification on the behaviour of marine animals (see Figure 9). Activities included: guessing the origin of plastic debris, a cartoon magnet game where pictures and text of behavioural changes caused by acidification needed to be matched together, and an activity involving wearing augmented reality goggles and performing a drawing task - intended to simulate ocean acidification affecting the senses of animals and hampering their daily lives.

Activity 8. Beach Walk: The aim of this activity was to introduce people to the wonders of sea creatures that can be found at their shores, and the threats that they face. A fixed workstation was set up with a display of local marine species alongside plastic debris and some alternative products for the reduction of personal plastic usage. We organized beachcombing sessions in which participants explored the Oban Bay strandline (see Figure 10). Interesting coastal species facts were shared, and species were identified. Each session finished with sampling a sandy area of the bay for microplastics and explaining the scientific protocol used for sampling. On return to the

Figure 8: Enjoying the touch and feel mystery boxes (photograph: Aquarela Images)

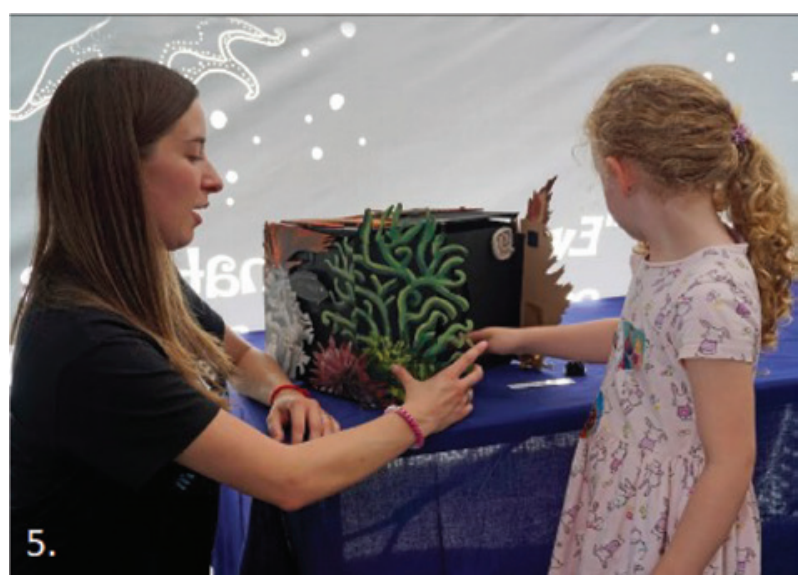


Figure 9: Understanding ocean acidification through a cartoon magnet game (photograph: Aquarela Images)

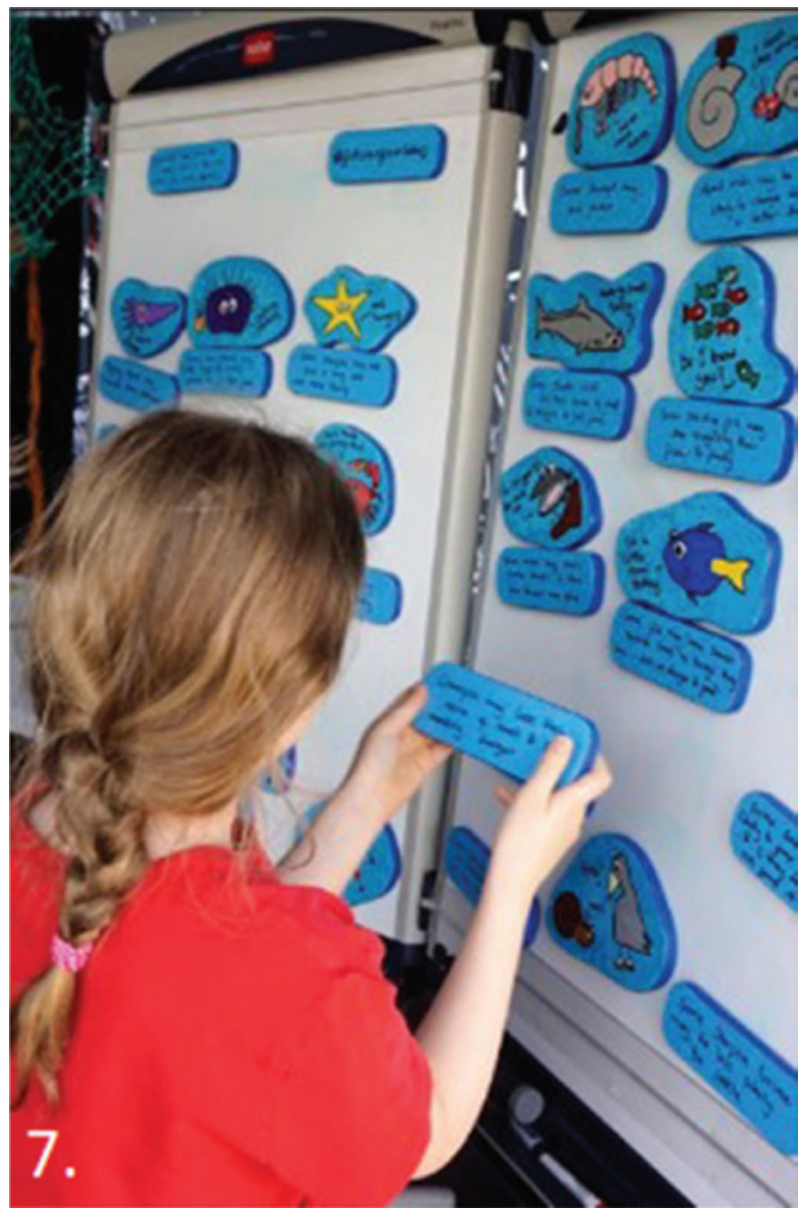

Figure 10: Beachcombing (photograph: Aquarela Images)

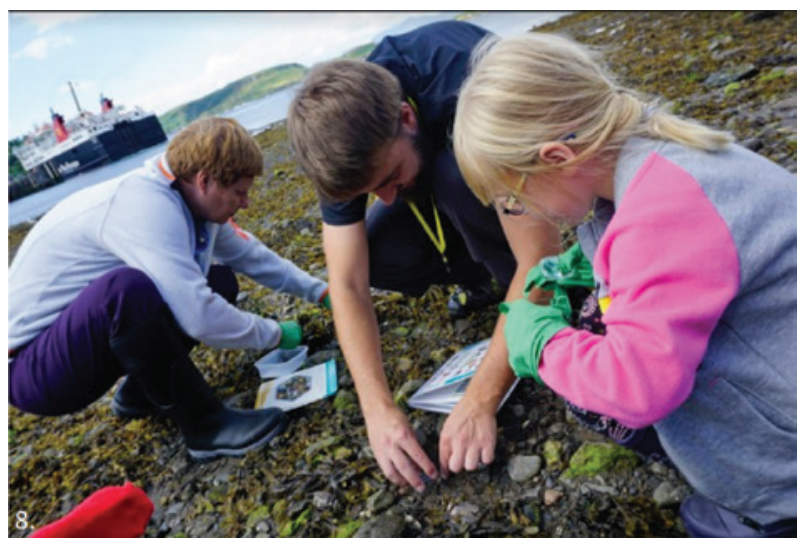

workstation, participants had the opportunity to view findings through a microscope and discuss further points of interest.

Activity 9. Journey of the Eel: Bringing awareness of the plight of the European eel with a treasure hunt/storytelling activity. The players had to choose a treasure at each station, and each treasure would take the players down a different story path, to explain the many difficulties eels face on their long migratory journeys. 
Activity 10. The Ocean Symphony Choir: The choir, formed from members of the passing public, aimed to connect its participants with the sounds of our underwater world through body percussion and voice, recreating sounds that can be heard underwater (waves and rain, those made by animals for communication, and the noise generated by human activities). Following a narrative set by the conductor, sections of the choir reproduced different elements of the ocean soundscape to highlight the importance of sound to animals and the effects that noise pollution can have on aquatic life.

\section{Audience engagement}

Participating in public engagement activities is known to have positive impacts on the public involved, such as gaining new skills and knowledge, increasing self-confidence and gaining satisfaction from making a difference (Ashcroft et al., 2016). Through feedback, we found that the public experienced similar benefits from participating in our activities. Our audience showed enthusiasm, curiosity and wonder about the topics we shared.

Children and parents were both equally engaged in our activities and eager to learn. The parents especially placed a lot of value on the scientific subjects and were eager for their children to fully understand the new concepts that were being presented to them. On leaving the tent from the Beautifully Strange activity, we invited all participants to complete a questionnaire. Over 95 per cent of the participants who initially reported feeling 'scared' by the 'ugly creatures' and 'weird alien animals' left the event thinking about them as 'beautiful', 'unique' and, most importantly, 'in need of protection'. This exhibition integrated art and science, and as a consequence of this interdisciplinary approach, we managed to evoke the same cognitive-emotional response to the more unusual deep-sea organisms that people would attach to more charismatic animals such as whales and dolphins.

\section{What the marine scientists learned from the public}

The activities used were adapted to use at future events based on feedback received from the public. For example, during the Natural Factory game (Activity 4, above), one person suggested we should use 3D puzzles to showcase the idea of 'lock and key', mimicking how a drug interacts with the target. Another person suggested we should use electronic devices, such as iPads, to store a wider variety of jigsaw games electronically. These suggestions were taken on board to create a new event called Build the Medicine, which was run at an outreach event in Dundee. This activity, which involved using iPads and 3D jigsaw puzzles, received more positive feedback from the audience and highlighted its effectiveness in delivering the message 'nature provides' to the public. Feedback obtained from this event has once again been used to update our activity so that it is ready to be used at future events. Using audience feedback can therefore add value to the continual development of a public engagement activity. We found audience feedback particularly helpful for reframing activities and fine-tuning the way we communicated our scientific topics to our audience.

The mussel game (Activity 1) was also adapted by introducing a time-lapse video of mussels' water filtration capacity and an anatomical diagram of a mussel. A short verbal presentation accompanied the introduction, which described the importance of mussels and other water-filtering animals in the marine environment. By including an introduction, we noticed that adults who brought children to play the game would stop to discuss marine science while the children engaged in the game itself. We therefore felt that this extended introduction was a useful addition to the game, as 
it helped convey the scientific message better and also engaged adults and children simultaneously.

\section{What the marine scientists and artists learned from collaborating}

The networking session with the artists and creative professionals led to two collaborations, Beautifully Strange (Activity 2, above) and Sounds of the West Coast (Activity 6, above). Below, the experiences of, and mutual benefits to, the scientists and artists are described.

\section{Beautifully Strange}

Beautifully Strange was an immersive, deep-sea experience that used textiles to build tactile connections between humans and an otherwise inaccessible environment that is often both 'out of sight and out of mind'. This exhibition was designed through a collaboration with Jessica Giannotti (a local marine scientist-cum-fashion designer, and founder of Crùbag, www.crubag.co.uk) and Dr Laura E. Hepburn (an oceanographic postdoctoral researcher). The inspiration for the activity arose from a conversation with the creative professionals during the networking session. Some of the creative professionals viewed the deep-sea animals as 'bizarre', 'alien' and 'ugly', while marine scientists conversely consider them to be beautiful. Laura and Jessica therefore chose to transform scientific video footage into emotive works of art, using textiles as a medium. They used eye-catching, colourful textiles, placed at the entrance to the ocean dome, to draw people towards the event itself. Many participants reported that this made them feel simultaneously 'welcomed and curious'. The idea was to allow people to physically pass through a gateway from the outer world, into a deep-sea environment, where they were surrounded by digital recordings of real hydrothermal vents and saltwater diffusers that reached out to all senses. The benefit of this collaboration was that it increased the impact and reach of Laura's research, by making it instantly accessible to a mixed audience, including young children, non-native English speakers, and individuals who are more comfortable with creative, rather than scientific, concepts. During the event, Crùbag assembled a trade stand selling textile fashion inspired by the marine environment alongside an interactive workshop where the public could create their own textile paintings. Young boys were particularly interested in the approach of merging marine science with textiles; they seemed fascinated by the concept behind Crùbag and the collections that were showcased. Even though the audience was excited to engage directly with the science presentations, it was the sense of ownership over their own creative images that really seemed to connect people to their deep-ocean surroundings. Since the textile paint took two hours to dry, Laura and Jessica were expecting many of the creations to have been left behind. However, all of the parents, without exception, came back to collect the textile canvas paintings created by their children during the workshops. The textile canvases were designed to keep the message alive at home and hopefully become a conversation starter, about deep-sea environments, marine issues, Crùbag and the event itself.

The symbiotic nature of the partnership was integral to the success of the project. As a researcher, Laura gained assistance with and inspiration for the event itself, a novel way of interpreting and disseminating future research, and a chance to reach an audience that would not normally have access to this type of research. Crùbag brings the unseen and normally inaccessible oceans into the awareness of the general public. Therefore, from Jessica's perspective, the collaboration fitted naturally 
within Crùbag's remit, and provided the opportunity to help early career scientists in their efforts to bring important science to the general public through art and creative workshops. Jessica gained new insights, further defined and developed her business practice from this experience, and evolved Crùbag's mission to spread ocean literacy, practise engagement and establish new collaborations. The initial networking event also provided the opportunity to meet and discuss potential projects with a range of early career scientists from many different marine science disciplines, providing Jessica with an important opportunity to increase her own scientific network.

\section{Sounds of the West Coast}

Sounds of the West Coast was an interactive seaweed sound art installation which was used to highlight how increasing underwater noise pollution from human activities around the west coast of Scotland may be affecting our oceans. This piece was developed through collaboration between scientists (Charlotte R. Findlay and Madlaina Michelotti) and the Templar Arts and Leisure Centre (TALC), a local group which aims to provide opportunities to children and young people interested in pursuing careers in creative arts and media education. It was during the networking event that the collaboration with TALC was established, and where discussions took place about how engaging multiple senses simultaneously could help to effectively increase public engagement.

Sounds of the West Coast (Figure 11) used a conductive seaweed installation, whereby seven dishes filled with seaweed and water were used to trigger (via a computer) seven different sounds when a hand was held over the dish or when the seaweed was touched. Sounds ranged from calming waves and dolphin whistles, to man-made noises, such as military sonar, shipping and seal scarers. These sounds could be overlaid to highlight how noisy ocean environments can become with more human activities. Thanks to the interactive nature of the piece, people were able to trigger and experience the effects of noise, which supported public understanding of the impact that marine activities can have on noise levels in our oceans.

\section{Figure 11: Sounds of the West Coast - seaweed in water connected to a touch board and computer (source: authors)}

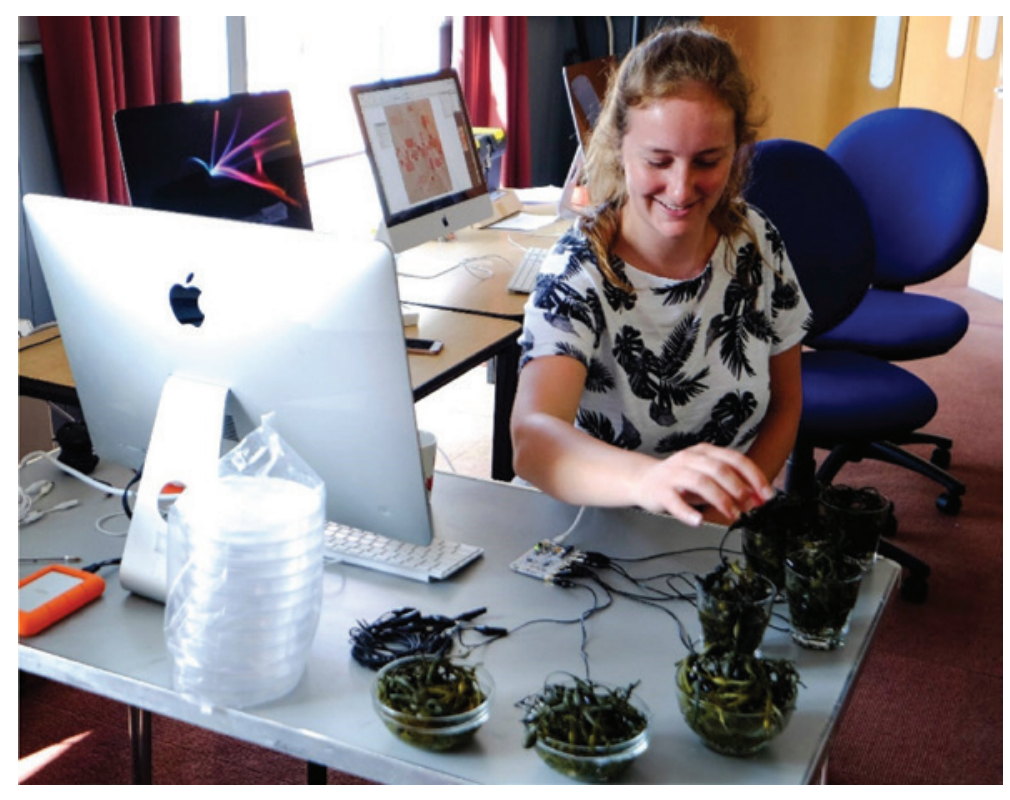


This collaboration provided us as scientists with an alternative way of thinking about how we interact with people, and how ideas can be formed by collaborating with people outside our own field who have more experience with engaging the public. This collaboration also benefited Grace Carroll, the young artist:

I think these collaborations are so important for young artists and scientists, because it helps us imagine ourselves in cross-disciplinary roles and practices ... where the specialisms of art, science and design interact. To have experienced early on, working with people who have different influences ... working in a way that is research-based and building these relationships is so important, and I think these projects bring young people closer to where they want to be, whilst bridging the gap between creative and scientific practices.

Nicole Heidtke, a tutor at TALC, reported that it was great to see Grace get an insight into the design of scientific research. Charlotte also acknowledged the quality and impact that a piece of so-called 'youth art' can have. The context of an art exhibition also certainly gave Charlotte the opportunity to find other audiences than those within the science-related community events. During the exhibitions, positive feedback was received from other arts organizations too - these organizations shared that it is very unusual for an art-science collaboration to work as well as 'Sounds of the West Coast' did. Nicole expressed her desire for more collaborations of this kind, and to have more dedicated time for the scientists and artists involved to work together to create an acknowledged and influential output:

Scientists who are creative will have broader views on their findings, see potential and will find better ways to engage with people. Artists who understand scientific research will take on the responsibility they have to protect the natural environment in the making of their designs. They will participate in a research informed through collaborative practice, before actually putting things into the world. For TALC and the young people involved, this project was a very valuable and inspiring experience.

This collaboration highlighted how useful and rewarding it can be to work with creatives to create effective and engaging science communication activities, and also how these collaborations may benefit those outside the field of science itself.

\section{Legacy and ongoing impact on the marine scientists' research}

This training was invaluable to our development as scientists as it provided us with skills and tools to create and deliver high-quality public engagement activities in the future. Due to the overwhelmingly positive public response to our public engagement activities, we also gained more confidence in developing scientific engagement activities for a variety of audiences. More generally, this training also provided us with professional skills, such as experience in science communication, public engagement, individual/teamwork, being creative, time management and prioritization.

Impressions of the activities were shared through news media coverage (Neil, 2018) social media (Twitter, Instagram, Facebook), a blog (Wheatley, 2018) and a photograph which was entered in the National Co-ordinating Centre for Public Engagement photography competition. The judges commented that 'this entry captured brilliantly the drama and excitement that great engagement can inspire' 
(NCCPE, 2018b). Such wide coverage was useful, as it helped to recognize our science and efforts in public engagement and spread our messages further. Our hope is that, through our engagement, dialogue around specific marine topics has inspired people, both directly and indirectly, to learn more and take action.

The FOOS programme has also impacted the way we present our research at conferences or in proposals, where we now focus on delivering more interactive presentations to engage and immerse our audience. For example, during the Beautifully Strange event, a discussion took place with an 11-year-old girl, where the scientist described how all of the animals have special adaptations that allow them to cope with life in the deep sea and on a hydrothermal vent. The girl said that she knew how the deep-sea snail felt because it had two homes - the shell on its back and the vent itself where all of its friends lived. In that way it was just like her and her family she lives in a community with her family and friends, but also has a caravan she can use to travel in during the holidays. Being confronted by these diverse views has changed the way the scientist approaches a lot of her research:

In research fellowship proposals that I write and present, I now add a 'human element' that connects us, as individual humans, to an aspect of the deep-sea environment. By personalizing my research, this enables people to see more clearly and convey the connectivity of all things, from deep-sea snails to a family on holiday in a camper van!

Improving the way in which we present our research can also have additional benefits as it is common for science dissemination to be evaluated in research project assessments, and it is considered critical for a fundable and outstanding project (Pohl et al., 2010). Therefore, by including public engagement and citizen science activities in research projects, more support and funding may be expected (Mea et al., 2016: 168).

The FOOS programme also led to the exploration of new scientific projects. For example, for Activity 5, Scotland's Cold-Water Coral Reef (the Mingulay Reef), a marine ecologist and chemist were paired to work together. We decided to focus on designing an activity around the benefits cold-water coral reefs provide for humans, with one of them being the discovery of new medicine in sponges:

Even though I was aware of this potential, it was never at the forefront of my mind. I experienced that the potential for medicine discovery in sponges really piqued the public's interest. As a direct consequence of these interactions, I have now planned a research expedition to collect deepsea sponges to study their compounds. This will allow us to learn about their ecology but also provide the potential for discovering medicines.

\section{Conclusions}

At the end of the FOOS programme, the FOOS consortium invited all participating scientists to join a two-day programme evaluation event. Almost half of the programme participants joined, and it was during this evaluation event that the idea emerged to share what the marine scientists learned during the FOOS programme and to reflect on the legacy it has in their work. With this account, the authors aim to encourage scientists to initiate similar collaborations with artists and engagement professionals as we have done.

This case study also aimed to address the lack of literature on the impacts of communication training on scientists, the process of developing public engagement 
activities and how public engagement works (Staley, 2017). It illustrates how scientists can acquire new knowledge from effective science communication training, which can change their perceptions, increase their skills in communicating with the public and change their attitude to public engagement (Staley, 2017; Staley et al., 2017: 20).

The Future of Our Seas project aimed to convey a training, engagement activity design and support programme which scientists can utilize or draw inspiration from when designing and creating their own outreach activities. By outlining both the training the marine scientists received as part of the programme and the experiences they had throughout the process, this case study highlights the benefits of collaborating with creative professionals to deliver successful and engaging outreach activities.

\section{Acknowledgements}

Our thanks go to the Natural Environment Research Council (NERC) who funded this initiative (NE/R01180X/1). The authors would like to express a very big thank you to all the FOOS consortium who dedicated their time to provide us with this training and unforgettable experience. Special thanks go to Kris De Meyer and Olivia Gray for reviewing the paper. Very importantly, we would also like to thank the community partners who engaged and collaborated with us, and all the people who interacted with us at our events! This study received funding from the European Union's Horizon 2020 research and innovation programme under grant agreement No. 678760 (ATLAS). This paper reflects the authors' views alone, and the European Union cannot be held responsible for any use that may be made of the information contained herein.

\section{Notes on the contributors}

Laurence De Clippele is a postdoctoral student at the University of Edinburgh. She is a marine ecologist who focuses on studying cold-water coral reefs with a general interest in biodiversity, biogeography, ecosystem function and pollution. She is especially interested in finding out why corals grow in certain places and not in others. She recently also started to specialize in benthic soundscapes and the potential of passive acoustic monitoring to manage the conservation of marine protected areas.

Madlaina Michelotti is an interdisciplinary marine scientist with a mix of natural and social science research experience. She completed a BSc in marine biology and oceanography at the University of Southampton and an MSc in ecosystem-based management of marine systems at the University of St Andrews. Currently, Madlaina is developing regional marine policies and facilitating stakeholder engagement as a marine planner.

Charlotte R. Findlay is a PhD student at the University of the Highlands and Islands (UHI) and Scottish Association for Marine Science (SAMS). Charlotte's work focuses on understanding and assessing the impact of underwater noise pollution on marine life. She is currently working to determine the risks posed to marine mammals from exposure to loud acoustic deterrent device (ADD) noise used at finfish aquaculture sites to deter seals.

Amy Cartwright has been a research assistant as part of the Marine Conservation Research Group at the University of Plymouth since 2015, supporting diverse projects ranging from the environmental impacts of marine renewables, sustainable 
aquaculture, and marine protected areas. Amy's research interests include mitigating human impacts on marine ecosystems and creating sustainable fisheries for the future. She is passionate about outreach work and communicating scientific outputs to the wider public.

Qing Fang received her MRes degree from University College London and a PhD from the University of Aberdeen, conducting research into natural products discovery under the supervision of Dr Hai Deng and Professor Marcel Jaspers. She held a postdoctoral position at the University of Copenhagen supervised by Professor Mani Arumugam. She is particularly interested in exploring new ways to communicate with audiences.

Charlie Wheatley holds a bachelor's degree in marine biology and oceanography, and a master's degree in climate change. Currently working as an environmental consultant, Charlie provides environmental project input across a wide range of disciplines, including flood risk, marine ecology, and climate change resilience. Charlie also volunteers with Incredible Oceans, where she helps to devise and run events aimed at helping the public become more ocean literate.

Ashleigh Sladen is a marine science enthusiast with a BSc (Hons) in marine biology and coastal ecology, and an MSc in sustainable aquaculture systems from the University of Plymouth. She currently works in the scientific publishing world, pursuing her passion for science communication.

Kes Scott-Somme is a freshwater research assistant at Earthwatch, where she mainly focuses on the FreshWater Watch project and connecting communities with water pollution issues. She has a master's degree in aquatic science from University College London, a BSc in marine biology from Portsmouth University and an FdSc in marine ecology and conservation from Sparsholt College. Kes has extensive volunteering experience in the environmental sector, and she has completed several training programmes including environmental leadership with UpRising.

Harry R. Harding is a marine behavioural ecologist, specializing in the effects of environmental change on marine fauna. Harry has been studying the effects of underwater anthropogenic noise on fish behaviour and physiology for the past six years, with the aim to identify real-world solutions. He completed a doctorate on the topic in 2020 and is currently an honorary research associate with the University of Bristol.

Juliette Jackson was awarded her $\mathrm{PhD}$ on the environmental design of coastal defences in 2015. While writing up her PhD, she also raised a family and carried out volunteer outreach at the school her children attended. In 2017, Juliette founded the non-profit community interest company Seadream Education. Seadream stands for Science and Engineering Around Devon, Research, Education and More! Seadream's mission is to bring exciting science and engineering outreach to instil passion, awe, knowledge, understanding and respect for the world around us.

Laura E. Hepburn is a postdoctoral researcher and award-winning science writer with over 14 years of engagement experience as a Hampshire STEAM ambassador and as a British Science Association CREST assessor. As a deep-sea oceanographer, she aims to connect humans with environments that are otherwise out of sight and out of reach. 
Jessica Giannotti is the founder and creative director of Crùbag, a Scotland-based lifestyle brand dedicated to spreading ocean literacy through beautifully crafted textiles. With a BSc (Hons) in marine science from SAMS-UHI, Jessica uses the interdisciplinary skill set to bridge the world of science and fashion/textiles, and has established relationships with scientists and research institutions around the world. Her company is based at the oldest independent marine institute in Scotland, the Scottish Association for Marine Science.

Grace Carroll is a young artist and former trainee at TALC, and is currently a communication design student at the Glasgow School of Art. In September 2019, Grace was involved in the Scotland+Venice programme at the 2019 Venice Biennale as an exhibition assistant for Charlotte Prodger's SAF05.

Nicole Heidtke studied fine arts and media and received a master's degree in cultural education. She previously taught at the Bauhaus University of Weimar (Germany). Together with Stefan Baumberger, she won the Berlin University of the Arts Award for Interdisciplinary Art and Science (2010). Art residencies include UCL Environment Institute, Aberdeen University Geoscience Department, University of Edinburgh Centre for Design Informatics. She and her partner lead the Creative Arts and Media programme at TALC, Tarbert.

Alison M. Worrall has worked for 28 years in Brazil with Christian non-governmental organizations in community development and coral reef and mangrove conservation. She is an underwater photographer and PADI dive master, and uses these abilities and experiences in educational opportunities combined with ocean literacy and art media activities with young people.

Kris De Meyer is a neuroscientist and science communicator, bringing knowledge of how brains and minds work to the communication of controversial topics such as climate change. He delivers engagement training for environmental scientists and policymakers, and runs science/policy co-production interventions at national and international levels to improve the communication of climate risk. He is co-producer of the documentary Right Between Your Ears and co-creator of interactive theatre piece The Justice Syndicate.

\section{References}

Andrews, E., Weaver, A., Hanley, D., Shamatha, J. and Melton, G. (2005) 'Scientists and public outreach: Participation, motivations, and impediments'. Journal of Geoscience Education, 53 (3), 281-93. https://doi.org/10.5408/1089-9995-53.3.281.

Ashcroft, J., Wykes, T., Taylor, J., Crowther, A. and Szmukler, G. (2016) 'Impact on the individual: what do patients and carers gain, lose and expect from being involved in research?' Journal of Mental Health, 25 (1), 28-35.

Baram-Tsabari, A. and Lewenstein, B.V. (2017) 'Science communication training: What are we trying to teach?'. International Journal of Science Education, Part B, 7 (3), 285-300. https://doi.org/10.1 080/21548455.2017.1303756.

Besley, J.C. and Tanner, A.H. (2011) 'What science communication scholars think about training scientists to communicate'. Science Communication, 33 (2), 239-63. https://doi.org/10.1177\%2F1075547010386972.

Besley, J.C., Dudo, A. and Storksdieck, M. (2015) 'Scientists' views about communication training'. Journal of Research in Science Teaching, 52 (2), 199-220. https://doi.org/10.1002/ tea.21186.

Cerrato, S., Daelli, V., Pertot, H., Puccioni, O. (2018) 'The public-engaged scientists: Motivations, enablers and barriers'. Research for All, 2 (2), 313-22. https://doi.org/10.18546/RFA.02.2.09. 
Cohn, N. (2013) 'Visual narrative structure'. Cognitive Science, 37 (3), 413-52. https://doi.org/10.1111/ cogs. 12016.

European Commission (2015) Indicators for Promoting and Monitoring Responsible Research and Innovation. Accessed 23 May 2019. http://ec.europa.eu/research/swafs/pdf/pub_rri/rri_ indicators_final_version.pdf.

Hamlyn, B., Shanahan, M., Lewis, H., O’Donoghue, E., Hanson, T. and Burchell, K. (2015) Factors Affecting Public Engagement by Researchers: A study on behalf of a consortium of UK public research funders. Accessed 19 November 2020. https://westminsterresearch.westminster.ac.uk/ item/q17q4/factors-affecting-public-engagement-by-researchers.

Hart, A. and Northmore, S.R. (2010) 'Auditing and evaluating university-community engagement: Lessons from a UK case study'. Higher Education Quarterly, 65 (1), 34-58. https://doi.org/10.1111/ j.1468-2273.2010.00466.x.

Hirsch, K. and Nisbet, M. (2007) Documentaries on a Mission: How nonprofits are making movies for public engagement. Future of public media project report. Accessed 19 November 2020. https://cmsimpact.org/resource/documentaries-on-a-mission-how-nonprofits-are-makingmovies-for-public-engagement/.

Jensen, P., Rouquier, J.B., Kreimer, P. and Croissant, Y. (2008) 'Scientists who engage with society perform better academically'. Science and Public Policy, 35 (7), 527-41. https://doi.org/10.3152/030234208X329130

Kim, E. (2016) 'Slack, the red hot $\$ 3.8$ billion startup, has a hidden meaning behind its name'. Business Insider India, 28 September. Accessed 23 May 2019. www.businessinsider.in/Slack-thered-hot-3-8-billion-startup-has-a-hidden-meaning-behind-its-name/articleshow/54554987.cms.

Koetsier, J. (2013) 'Flickr founder Steward Butterfield's new Slack signed up 8,000 companies in 24 hours'. VentureBeat, 15 August. Accessed 23 May 2019. https://venturebeat.com/2013/08/15/ flickr-founder-stewart-butterfields-new-slack-signed-up-8000-companies-in-24-hours/.

Kwok, R. (2013) 'Communication: Two minutes to impress'. Nature, 494 (7435), 137-8. https://doi.org/10.1038/nj7435-137a.

Lee, S.Y., Mott, B.W. and Lester, J.C. (2010) 'Optimizing story-based learning: An investigation of student narrative profiles'. In V. Aleven, J. Kay and J. Mostow. (eds), Intelligent Tutoring Systems, Lecture Notes in Computer Science, vol. 6095. Berlin: Springer, 155-65. https://doi.org/10.1007/978-3-642-13437-1_16.

Maibach, E. (2012) 'Knowing our opinions for setting the record straight, when doing so is particularly important'. Psychology Science in the Public Interest, 13 (3), 105. https://doi.org/10.1177\%2F1529100612457647.

Mayer, A. and Smith, E.K. (2019) 'Unstoppable climate change? The influence of fatalistic beliefs about climate change on behavioural change and willingness to pay cross-nationally'. Climate Policy, 19 (4), 511-23. https://doi.org/10.1080/14693062.2018.1532872.

Mea, M., Newton, A., Uyarra, M.C., Alonso, C. and Borja, A. (2016) 'From science to policy and society: Enhancing the effectiveness of communication'. Frontiers in Marine Science, 3, article 168, 1-17. https://doi.org/10.3389/fmars.2016.00168.

Myers, T.A., Maibach, E., Peters, E. and Leiserowitz, A. (2015) 'Simple messages help set the record straight about scientific agreement on human-caused climate change: The result of two experiments'. Plos One, 10 (3), e0120985. https://doi.org/10.1371/journal.pone.0120985.

NCCPE (National Co-ordinating Centre for Public Engagement) (2018a) 'Evaluation resources'. Accessed 23 May 2019. www.publicengagement.ac.uk/do-engagement/evaluating-publicengagement/evaluation-resources.

NCCPE (National Co-ordinating Centre for Public Engagement) (2018b) 'Images of public engagement 2018'. Accessed 23 May 2019. www.publicengagement.ac.uk/nccpe-projects-andservices/images-public-engagement-2018.

Neil, S. (2018) 'Scientists explain the future of our seas'. Oban Times, 31 July. Accessed 23 May 2019. www.obantimes.co.uk/2018/07/31/the-future-of-our-seas/.

Perkel, J.M. (2017) 'How scientists use Slack'. Nature, 541 (7635): 123. https://doi.org/10.1038/541123a.

Pincus, A. (2007) 'The perfect (elevator) pitch'. Bloomberg Business Week, 18 June. Accessed 20 November 2020. www.bloomberg.com/news/articles/2007-06-18/the-perfect-elevatorpitchbusinessweek-business-news-stock-market-and-financial-advice.

Pohl, C., Perrig-Chiello, P., Butz, B., Hirsch Hadorn, G., Joye, D., Lawrence, R., Nentwich, M., Paulsen, T., Rossini, M., Truffer, B., Wastl-Walter, D., Wiesmann, U. and Zinsstag, J. (2010) Questions to Evaluate Inter- and Transdisciplinary Research Proposals. Working paper, td-net for Transdisciplinary Research, Berne. Accessed 20 November 2020. www.transdisciplinarity.ch/ td-net/Publikationen/Publikationen-td-net/mainColumnParagraphs/04/text_files/file/document/ td-Evaluation2011_workingpaper.pdf. 
Rapley, C. and De Meyer, K. (2014) 'Climate science reconsidered'. Nature Climate Change, 4 (9), 745-6. https://doi.org/10.1038/nclimate2352.

Rose, C. (2011) What Makes People Tick: The three hidden worlds of settlers, prospectors and pioneers. Kibworth Beauchamp: Matador.

Staley K. (2017) 'Changing what researchers "think and do": Is this how involvement impacts on research?' Research for All, 1 (1), 158-67. https://doi.org/10.18546/RFA.01.1.13.

Staley, K., Abbey-Vital, I. and Nolan, C. (2017) 'The impact of involvement on researchers: A learning experience'. Research Involvement and Engagement, 3 (1), 1-9. https://doi.org/10.1186/s40900017-0071-1.

Wheatley, C. (2018) 'Future of our seas'. 29 July. Accessed 23 May 2019. https://resolve-or-dissolve. blogspot.com/2018/07/future-of-our-seas-part-1.html. 